\title{
Influence of extruder screws speed and process temperature on the extrudate shape changes of the maize-spelt blends
}

\author{
Żelaziński Tomasz ${ }^{1, *}$, Ekielski Adam ${ }^{1}$, Siwek Adam ${ }^{2}$, and Słoma Jacek ${ }^{1}$ \\ ${ }^{1}$ Department of Production Management and Engineering. Warsaw University of Life Sciences- SGGW, ul. Nowoursynowska \\ 164, 02-787 Warsaw, Poland \\ ${ }^{2}$ Food Technology and Gastronomy Institute, Lomza State University of Applied Sciences, Akademicka 14, 18-400 Łomża, \\ Poland
}

\begin{abstract}
The objective of the study was examination of changes in the shape factors of extruded products, which occur as a result of different settings of the extrusion process variables. Samples analysed included products created by means of the extrusion process from a mixture of spelt flour and cornmeal, with the share of spelt at 70 to $100 \%$. The samples were made with the use of a corotating twin screw extruder. Two speeds of extruder screw rotation (300 and $350 \mathrm{rpm}$ ) as well as two levels of temperature $\left(120\right.$ and $\left.140^{\circ} \mathrm{C}\right)$ were set during the investigation. The samples obtained were photographed in a light box, following which they underwent an image analysis with the use of specialist vision software. Four shape-related factors were determined: area, elongation factor, Heywood circularity factor and compactness factor. It was determined that the product shape changed significantly depending on the share of spelt flour in the mixture. Moreover, it was observed that change in the screw rotation speed within the analysed range may cause material changes in the shape of particular extrudates.
\end{abstract}

\section{Introduction}

The shape of extruded products is of significant importance not only due to typically marketing aspects, but also from the technical perspective related to further processing thereof. Authors of numerous publications indicate that an evenly porous structure on the products may, for example, improve adhesion of various spices applied at further stages of the production process [1]. Properly selected shape and granulation of products used as toppings may also enable thorough covering of foods $[2,3]$. Other shape parameters of products are needed for optimum selection of the grinder or classifier sieves on the production line of, for example, extruded edible coating crumbs $[2,4]$. Therefore, the product shape is a parameter which may eventually influence efficiency of subsequent technological processes $[5,6]$. Despite numerous advantages of the extrusion process, production of extruded products characterised with regular and repeatable shapes is not an easy process and is still the subject of many studies [7]. In fact, the final product shape depends on numerous parameters of the extrusion process, including composition and humidity of the mixture, process temperature, screw geometry and rotational speed or die nozzle geometry $[8,9,10,11]$. If a cutter is used, setting of the knife rotational speed is also important. Thus, to ensure a regular shape of manufactured products, constant process monitoring is necessary, e.g. with the use of vision systems, and a quick response to extrusion process disruptions. Consequently, the application of quick vision techniques opens new possibilities of extrusion process control, involving simultaneous product quality control and provision of feedback allowing process adjustment and control.

The introduction of quick vision based analysis with the use of specialist software is, consequently, the subject of numerous studies related to the production process of not only extruded products, but also many other foods $[12,13,14]$. Not only do studies in this area cover investigations into the external shape of products, but also into the shape of pores making up the internal product structure. More detailed analyses include research into the internal 3D product structure $[15,16]$.

Thus, the objective of the study was to investigate into changes in selected shape parameters of the whole extruded products, which occur as a result of different extrusion process variables settings.

\section{Materials and Methods}

\subsection{Materials and extrusion - cooking}

The material used in the investigation was spelt flour and cornmeal (granulation: $0.16-0.60 \mathrm{~mm}$ ). The products were purchased on the local market, Poland.

* Corresponding author: tomasz_zelazinski@sggw.pl 
Table 1. Characteristics of raw materials used in the experiment.

\begin{tabular}{|l|l|l|}
\hline $\begin{array}{l}\text { Raw } \\
\text { material }\end{array}$ & $\begin{array}{l}\text { Corn groats } \quad[\% \\
\text { d.m.] }\end{array}$ & Spelt [\% d.m.] \\
\hline Moisture & $13,4 \pm 0.34$ & $13,2 \pm 0.33$ \\
\hline Starch & $74 \pm 1.85$ & $56,5 \pm 1.425$ \\
\hline Proteins & $8.3 \pm 0.21$ & $11,7 \pm 0.29$ \\
\hline Total fat & $0.7 \pm 0.02$ & $2,6 \pm 0.17$ \\
\hline
\end{tabular}

Mixture compositions were prepared using the above ingredients, with spelt flour as the main component at $70,80,90$ and $100 \%$. The mixtures were prepared in a ribbon mixer where the ingredients were additionally dampened to the moisture level of $14 \%$. Before commencement of the extrusion process, moisture level control of the dampened material was performed with the use of a WPS 210 moisture balance with the accuracy of $0.001 \mathrm{~g}$ (prod.: Radwag). Prepared as above, the material was thermally processed in an Evolum 25 twin screw extruder (prod.: CLEXTRAL, France) with the screw length to diameter ratio of L:D 27:1. The extruder matrix contained one round outlet opening with the diameter of $2.5 \mathrm{~mm}$. In the tests, the plasticising section temperature was set at 120 and $140{ }^{\circ} \mathrm{C}$. The distribution of temperatures in the extruder cylinder (from the plasticising section to the feeding section, respectively) was $120,120,110,90,80,60$ and 140 , 120, 110, 90, 80, $60{ }^{\circ} \mathrm{C}$. Extruder screw rotation was changed during the tests, at 300 and $350 \mathrm{Rpm}$. Material flow rate: $5.5 \mathrm{~kg} . \mathrm{h}-1$. The extruder head was equipped with a three-legged cutter, which enabled creation of products with the length of $7.5 \mathrm{~mm} \pm 0.5 \mathrm{~mm}$. After cooling, extrudates were stored in plastic bags.

\subsection{Extrudate properties}

The subsequent stage of the investigation involved photographing of randomly selected whole extrudate samples. This was performed with the use of a light boxed fitted with Philips daylight fluorescent lamps with the colour temperature of D65 and a colour Basler A2500 - 14uc (5Mpx) camera (producer: Basler, Ahrensburg, Germany). Before the test, the samples were placed on black paper so that they did not touch each other's edges. Particular photographs were taken in 5 repetitions (a single set consisted of 50 samples). Acquisition of the photographs was performed with the camera software (pylon Viewer). Subsequently, the photographs taken were subjected to a detailed 2D vision analysis with the use of $\mathrm{Ni}$ Vision Assistant 2015 (Producer: National Instruments, USA), with 4 identified fators characterising the features of extruded product shape: Area, Elongation Factor, Heywood Circularity Factor and Compactness Factor (Equations 1, 2, 3).

$$
\begin{gathered}
\text { Elongation Factor }=\frac{F}{R F_{b}} \\
\text { Compactness Factor }=\frac{A}{W \cdot H} \\
\text { Heywood Circularity Factor }=\frac{P}{2 \sqrt{\pi A}}
\end{gathered}
$$

Where:

A - Area

W - Bounding Rect Width

$\mathrm{H}$ - Bounding Rect Height

F - Max Feret Diameter

$\mathrm{RF}_{\mathrm{b}}$ - Equivalent Rect Short Side (Feret)

$\mathrm{P}$ - Perimeter

Calculation of particular factors was carried out pursuant to the methods outlined in the IMAQ Vision Concepts Manual 2005. Image analysis covered three levels of image transformation, which were used for analysing subsequent tested samples (Fig. 1). The figures obtained were subjected to Annova statistical analysis and correlation factors were identified, with the data presented in a box-plot. Data analysis was performed with the StatSoft, Inc. (2013), STATISTICA software.

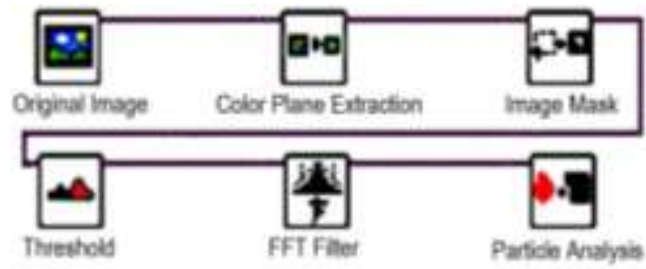

Fig. 1. Tools and settings applied in the Ni Vision Assistant image analysis. Color Plane extraction (RBG Red Plane), Threshold (Manual Threshold Range - 52), FFT Filter (Truancation frequency - 15\%, Mode - Low pass).

\section{Results and discussion}

Analysis of the investigation results led to an observation that the size and shape of extruded products changed along with changes in the share of spelt in the mixture and extrusion process parameters. Significant changes were observed in all analysed samples. In the case of Area analysis of photographed extrudate samples, it was stated that the Area of particular samples, fig. $2 a$ and $2 b$, increased along with a decreasing share of spelt in the mixture (irrespective of changes in the temperature and rotation of the extruder screw). This can be justified as increase in the share of cornmeal in the mixture (typical structure building ingredient) contributes to growth in expansion parameters (e.g. radial expansion) of many extruded cereal ingredients, including wheat [10, 17]. Therefore, based on the analysis of a single factor namely, the area of photographed products - one can state whether change in process parameters involves any change in external "visual" quality parameters of the extrudates

Table 1. Correlation coefficients for spelt share (70, 80, 90 and $100 \%$ ) in the mixture according to various shape coefficients. 


\begin{tabular}{|c|c|c|c|c|}
\hline Variable & $\begin{array}{c}\text { Extrudate } \\
\text { produced } \\
\text { at temp. } \\
120{ }^{\circ} \mathrm{C}, \\
\text { screws } \\
\text { speed } 300 \\
\text { Rpm }\end{array}$ & $\begin{array}{c}\text { Extrudate } \\
\text { produced } \\
\text { at temp. } \\
140{ }^{\circ} \mathrm{C}, \\
\text { screws } \\
\text { speed } 300 \\
\text { Rpm }\end{array}$ & $\begin{array}{c}\text { Extrudate } \\
\text { produced } \\
\text { at temp. } \\
120^{\circ} \mathrm{C}, \\
\text { screws } \\
\text { speed } 350 \\
\text { Rpm } \\
\end{array}$ & $\begin{array}{c}\text { Extrudate } \\
\text { produced } \\
\text { at temp. } \\
140{ }^{\circ} \mathrm{C}, \\
\text { screws } \\
\text { speed } 350 \\
\text { Rpm } \\
\end{array}$ \\
\hline Area $\left[\mathrm{mm}^{2}\right]$ & $0.931 *$ & $0.926^{*}$ & $0.863 *$ & $0.904 *$ \\
\hline \begin{tabular}{|l} 
Elongation \\
Factor \\
\end{tabular} & $-0.949 *$ & $-0.902 *$ & $0.783 *$ & $0.785^{*}$ \\
\hline \begin{tabular}{|l|} 
Heywood \\
Circularity \\
Factor
\end{tabular} & $-0.921 *$ & $-0.898 *$ & $0.876^{*}$ & $0.709 *$ \\
\hline $\begin{array}{l}\text { Compactness } \\
\text { Factor }\end{array}$ & $0.928 *$ & $0.939 *$ & $-0.709 *$ & $-0.731^{*}$ \\
\hline
\end{tabular}

Correlation coefficients are significant for $\mathrm{p}<0.05 . *$ - for any spelt share in the compound measure were been 5 repeated.

As variability in particular items is very high (correlation factor from 0.931 to 0.863 for different process settings), this may be at the same time a very sensitive quality indicator (table 2). Analysis of the area of photographed samples is, however, not a very precise parameter and, therefore, other factors defining the extrudate shape were included in subsequent tests.

a)

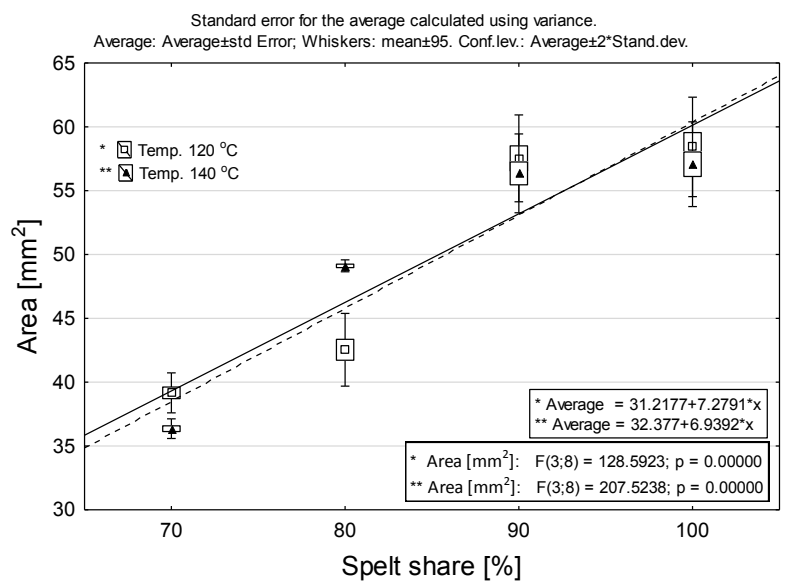

b)

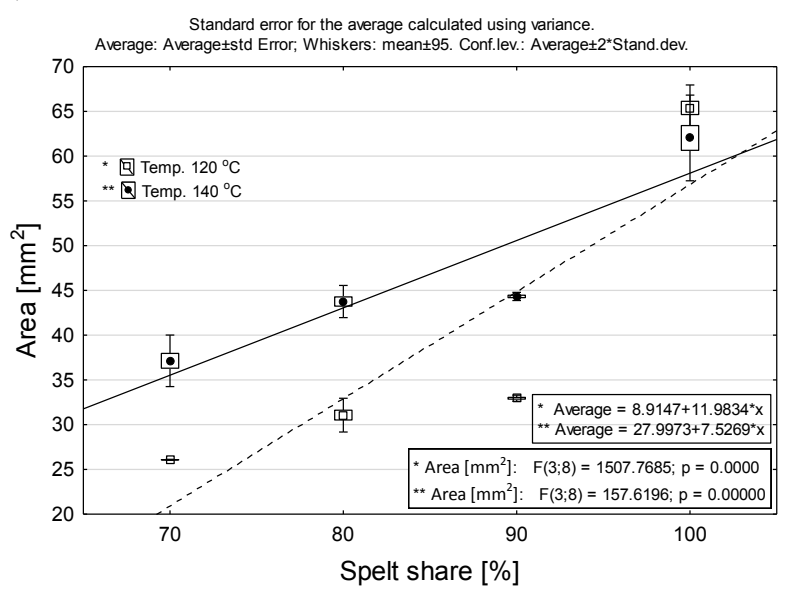

Fig. 2. Effect of spelt flour in extruded blend on the "Area" coefficient extrudates: a) extruder screw rotation $300 \mathrm{Rpm} . \mathrm{b}$ ) extruder screw rotation $350 \mathrm{Rpm}$. Test $\mathrm{F}$ results and values (ANOVA) are presented for each temp. process.
Figures $3 \mathrm{a}$ and $3 \mathrm{~b}$ illustrate changes in the extrudate Eongation Factor. It was determined that at extruder screw rotation speed of $300 \mathrm{Rpm}$, the Elongation Factor fell along with increase in the share of spelt in the mixture, whereas at extruder screw rotation speed of 350 Rpm, values of the factor increased. Thus, assuming that other process parameters will not be changed, increase in screw rotation speed itself allows obtaining a product characterised with different elongation degrees. It was moreover determined that the elongation factor changed as a result of temperature increase from 120 to $140{ }^{\circ} \mathrm{C}$, yet the changes were not as intensive as in case of the other parameters. However, an opposite influence of temperature onto the elongation factor was found for samples produced at the screw rotation speed of 350 $\mathrm{Rpm}$. The correlation factor for samples obtained at the screw rotation speed of $300 \mathrm{Rpm}$ was high at -0.949 and -0.902 , whereas at the screw rotation speed of $350 \mathrm{Rpm}$ the correlations were 0.783 and 0.782 . Elongation factor tests and other shape factors on food products were also performed [18]. The equivalent for the sample elongation visual tests is the extrudate lengthwise expansion factor. Investigations of this kind are commonly described in the literature and they cover changes in lengthwise expansion as a result changes in the mixture parameters, screw rotations, nozzle geometry, process temperature or mixture moisture $[19$, $20]$.

a)

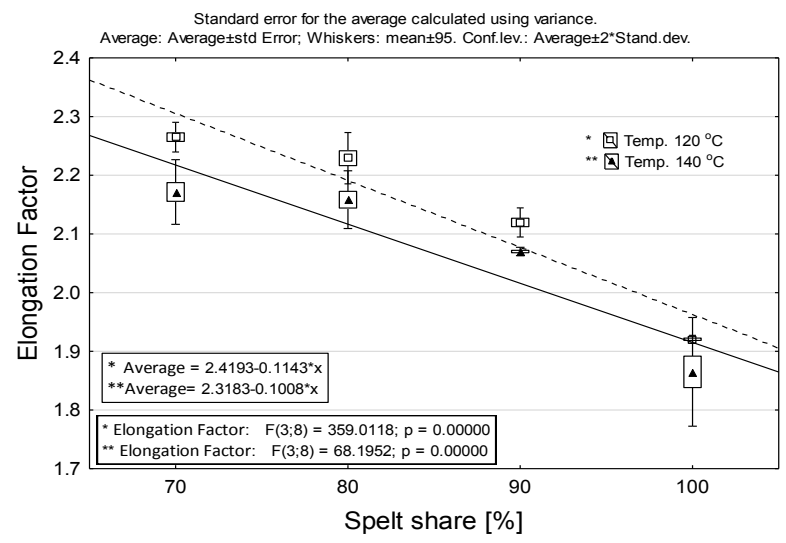

b)

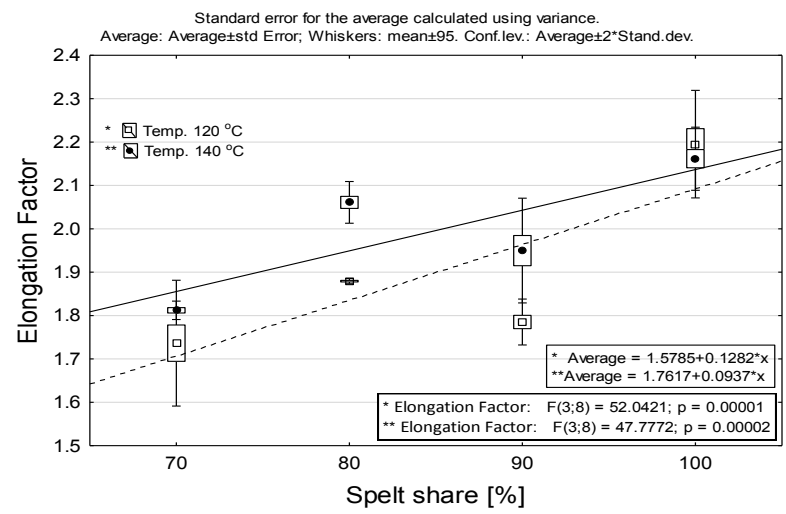

Fig. 3. Effect of spelt flour in extruded blend on the Elongation Factor extrudates: a) extruder screw rotation $300 \mathrm{Rpm}$. b) extruder screw rotation $350 \mathrm{Rpm}$. Test $\mathrm{F}$ results and values (ANOVA) are presented for each temp. process. 
Figures $4 \mathrm{a}$ and $4 \mathrm{~b}$ illustrate changes in the circularity factor for particular extruded products. In these investigations, the parameter defines the possibility to achieve a round shape of extruded products with the use of a round nozzle. It was determined that, along with an increasing share of spelt in the mixture, the circularity factor at the pre-set screw rotation speed of $300 \mathrm{Rpm}$ was decreasing towards the value of 1 and, therefore, products with a higher share of spelt are more round. Significance of the changes is confirmed by the high correlation factor at -0.921 and -0.898 , respectively. On the other hand, increase in the rotation speed to $350 \mathrm{Rpm}$ has an opposite effect (increase in the value of this parameter along with growing share of spelt); thus, the product will have a less round shape (correlation factor of 0.876 and 0.709 ). It was also found that temperature change from 120 to $140^{\circ} \mathrm{C}(350 \mathrm{rpm})$ in the case of spelt share at 70 and $80 \%$ involves an increase in the circularity factor value. This phenomenon is also opposite as compared with the result of test performed at the rotation speed of $300 \mathrm{rpm}$ and proves that, in this case, temperature change in combination with changes in rotation may also have significant impact onto the shape of extruded products. The circularity coefficient studies are common in extruded products research in both the food and pharmaceutical industries [21].

a)

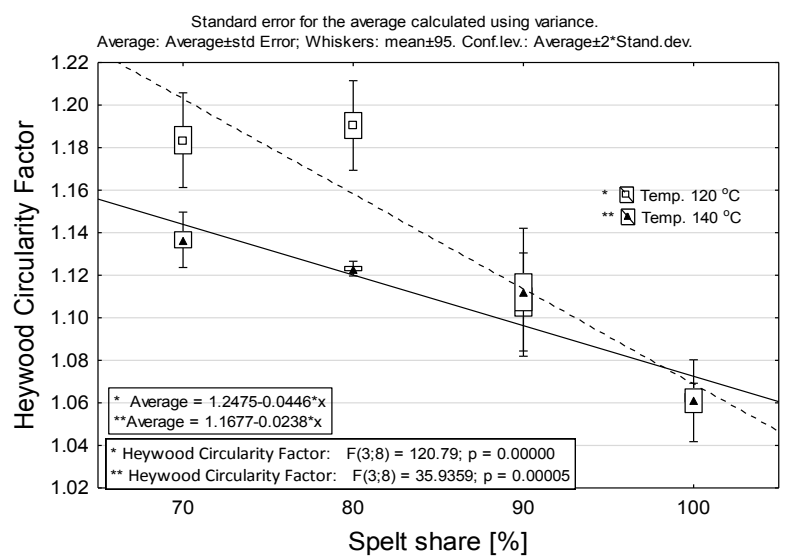

b)

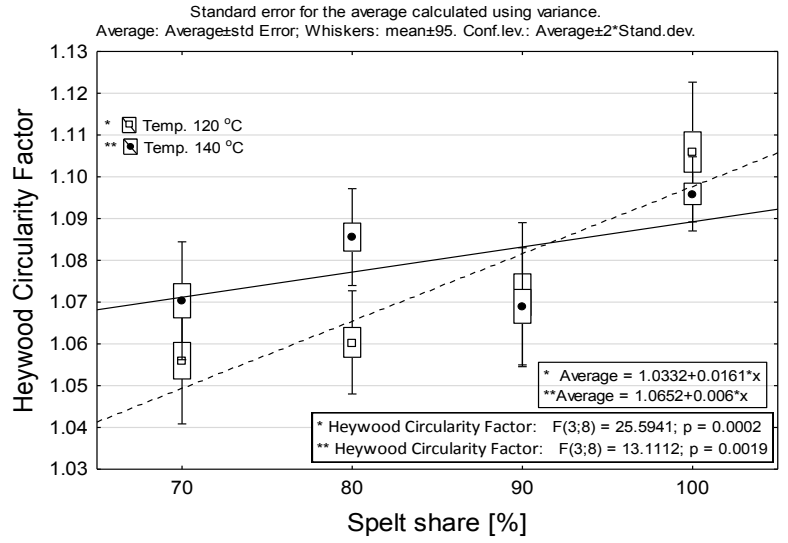

Fig. 4. Effect of spelt flour in extruded blend on the Heywood Circularity Factor extrudates: a) extruder screw rotation 300 Rpm. b) extruder screw rotation $350 \mathrm{Rpm}$. Test $\mathrm{F}$ results and values (ANOVA) are presented for each temp. process.
Figures $5 \mathrm{a}$ and $5 \mathrm{~b}$ illustrate the results of compactness factor analyses. The investigations demonstrated clearly that change in the extruder screw rotation speed had clear influence onto that parameter, which is indicated by high differences in the course of charts for the rotation speeds of $300 \mathrm{Rpm}$ (growing values) and $350 \mathrm{Rpm}$ (falling values). In this case also, variability of results was characterised by high correlation factors at, respectively, 0.928 and 0.939 . Another noticeable element was the influence of temperature which, at increased screw rotation speed, resulted in an increased value of the factor (Heywood circularity factor). Thus, also in this case, a change in the range of rotation speed and temperature dramatically changes the shape of extruded products.

a)

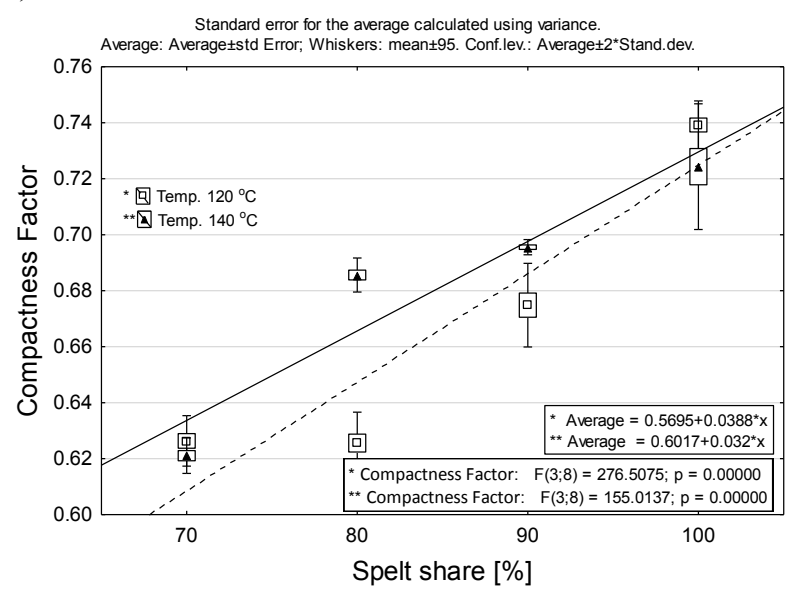

b)

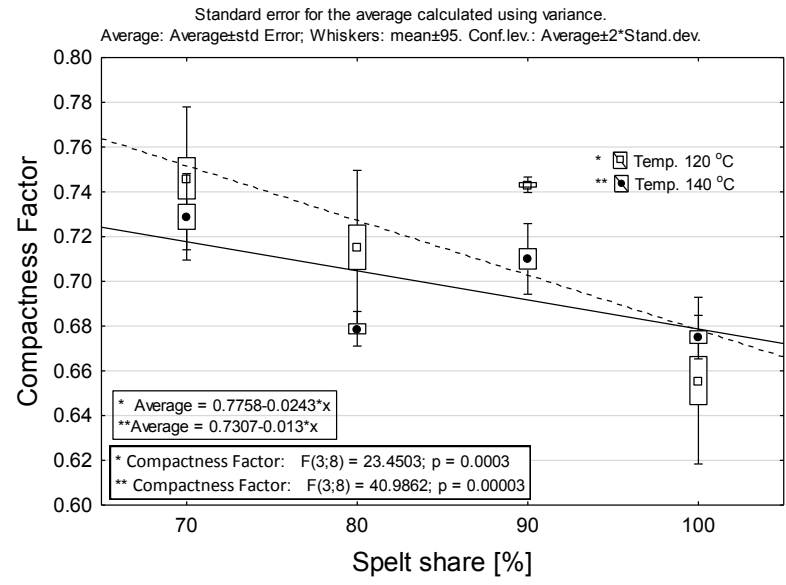

Fig. 5. Effect of spelt flour in extruded blend on the Compactness Factor extrudates: a) extruder screw rotation 300 Rpm. b) extruder screw rotation $350 \mathrm{Rpm}$. Test $\mathrm{F}$ results and values (ANOVA) are presented for each temp. process.

The compactness factor defines the shape of product which allows best adaptation of particular extrudates to one another and, therefore, the higher the value of the factor, the higher number of similar products will fit within a given area. Determination of the value of this factor has a particular useful meaning, e.g. in case of application of such products as topping or semi-products in layered products. 


\section{Conclusions}

The extrusion process parameters which determine significant changes in the shape factors are mainly the mixture composition (spelt/corn) and the extruder screw rotational speed. It was determined that change in the screw rotational speed from 300 to $350 \mathrm{Rpm}$ may have an opposite influence onto changes of extruded product shape factors. Thus, changing the screw rotational speed alone may involve a significant change of the extruded product shape, e.g. from round to elongated. Along with changes in the rotational speed of the screw, opposite influence of temperature onto the final product shape is observed. Vision analysis considering the sample area and elongation factor, Heywood circularity factor and compactness factor provides important information regarding the influence of changes in the extrusion process parameters onto shaping of extruded products.

\section{References}

1. S.W. Rosenthal, U.S. Patent No. 4,943,438. Washington, DC: U.S. Patent and Trademark Office, (1990).

2. C.K. Kamalakanth, J. Bindu, K. Bijith, C.N. Ravishankar, T.K.S. Gopal, Development and comparison of extruded breading with conventional bread crumbs for coating fish balls. ICAR, (2013).

3. L. Strauta, S. Muižniece-Brasava, I. Gedrovica, Chemical Technology 66, 1, 34-39 (2015).

4. S. Muley, T Nandgude, S. Poddar, Asian Journal of Pharmaceutical Sciences 11, 6, 684699. (2016)

5. A.M. Bouwman, J.C. Bosma, P. Vonk, J.H.A. Wesselingh, H. W. Frijlink. Powder Technology 146, 1, 66-72 (2004)

6. A. Ekielski, T. Żelaziński, P. Zdanowska, I. Florczak, INMATEH-Agricultural Engineering, 43, 2 (2014)

7. J. Fan, J.R. Mitchell, J. Blanshard, International journal of food science \& technology 31, 1, 5565 (1996)

8. L. Alvarez-Martinez, K.P. Kondury J.M. Harper, Journal of Food Science 53, 2, 609-615 (1988)

9. C.I. Moraru, J.L. Kokini, Comprehensive Reviews in Food Science and Food Safety 2, 4, 147-165 (2003)

10. Q.B. Ding, P. Ainsworth, A. Plunkett, G. Tucker, H. Marson, Journal of Food Engineering 73, 2, 142-148. (2006)

11. H. Cheng, A. Friis, Food and Bioproducts Processing 88, 2, 188-194 (2010)

12. T. Brosnan, D.W. Sun, Journal of food engineering 61, 1, 3-16 (2004).

13. C.J. Du, D.W. Sun, Journal of food engineering 72, 1, 39-55 (2006)

14. C.L.S Lau, Q. Yu, V.Y. Lister, S.L. Rough, D.I. Wilson, M. Zhang, Chemical Engineering Research and Design 92, 11, 2413-2424 (2014)
15. P. Babin, G. Della Valle, R. Dendievel, D. Lourdin, L. Salvo, Carbohydrate polymers 68, 2, 329-340 (2007)

16. P. M. Falcone, A. Baiano, F. Zanini, L., Mancini, G. Tromba, D. Dreossi, M.A.D. Journal of Food Science 704 (2005)

17. A. Arhaliass, J. Legrand, P. Vauchel, F. FodilPacha, T. Lamer, J.M. Bouvier, Food and Bioprocess Technology 2, 2, 186-193 (2009)

18. C. Costa, F. Antonucci, F. Pallottino, J. Aguzzi, D.W. Sun, P. Menesatti, Food and Bioprocess Technology 4, 5, 673-692 (2011)

19. G. Shirani, R. Ganesharanee, Journal of food engineering 90,1, 44-52 (2009)

20. T. Żelaziński, Annals of Warsaw University of Life Sciences-SGGW, 57, 49-55 (2011)

21. S. Almeida-Prieto, J. Blanco-Méndez F.J. Otero-Espinar, Journal of pharmaceutical sciences, 93, 3, 621-634. (2004) 